\title{
INTERPRETAÇÃO QUALITATIVA DE RESULTADOS QUANTITATIVOS: UMA ANÁLISE DE ASPECTOS METODOLÓGICOS NA COMPARAÇÃO DE DIFERENTES PESQUISAS
}

\author{
QUALITATIVE INTERPRETATION OF QUANTITATIVE RESULTS: AN ANALYSIS \\ OF METHODOLOGICAL ASPECTS IN THE COMPARISON BETWEEN DIFFERENT \\ RESEARCHES
}

Tatiana Schwochow Pimpão Universidade Federal do Rio Grande Doutoranda do Programa de Pós-graduação em Linguítica - UFSC

Edair Maria Görski Universidade Federal de Santa Catarina

\begin{abstract}
Resumo
A comparação de resultados de pesquisas sociolinguísticas fornece indicadores que permitem uma melhor compreensão de um mesmo objeto de estudo, contribuindo para a descrição da língua em análise. Neste artigo, levantamos alguns problemas concernentes a comparações estabelecidas entre resultados de dois trabalhos sobre o uso variável do modo subjuntivo em diferentes comunidades brasileiras, alertando para o fato de que (i) análises comparativas devem considerar especificidades metodológicas, como, por exemplo, o perfil social dos informantes envolvidos, o tamanho da amostra e os fatores controlados; (ii) o pesquisador deve ser cauteloso quanto à formulação de generalizações a partir da interpretação de resultados comparativos frequenciais.
\end{abstract}

Palavras-chave: Variação. Modo verbal. Comparação de resultados. Análise interpretativa.

\begin{abstract}
The comparison between results of sociolinguistic studies provides indicators that allow a better understanding of a certain object of study, contributing to the description of the language that is being analysed. In this paper, we consider some problems that emerge from the comparison between two researches on the variable use of the subjunctive mood in different brazilian communities, highlighting that (i) well done comparative analysis must consider methodological specifics, such as the social characteristics of the informants, the size of the samples and the controlled factors; (ii) the researcher must be careful not to make generalizations on the basis of comparative results of general frequency.
\end{abstract}

\section{INTRODUÇÃO}

A Sociolinguística Variacionista tem como objeto o estudo da estrutura e da evolução da linguagem dentro do contexto social da comunidade de fala, buscando observar e descrever a regularidade de fenômenos de variação, ou seja, padrões regulares de uso linguístico na comunidade que possam ser abstraídos de manifestações linguísticas 
individuais. Nesse sentido, há uma valorização do rigor metodológico, seja quanto à busca dos informantes que fornecerão dados reais de uso e a seleção dos dados para análise, seja quanto à análise quantitativa empreendida.

Segundo essa perspectiva teórica, o sistema linguístico é de natureza probabilística, o que requer do pesquisador a utilização de técnicas quantitativas para captar as regularidades que o regem. No âmbito das pesquisas variacionistas, utiliza-se uma ferramenta estatística específica para o estudo de regras variáveis (VARBRUL 2S e suas novas versões GoldVarb). Esse pacote realiza análises multivariadas apontando correlações entre um conjunto de variáveis independentes e a variável dependente - 0 objeto variável em análise; mais especificamente mostrando o efeito dos fatores controlados sobre o uso das formas variantes. Fornece ainda frequências, percentuais, pesos relativos e níveis de significância das variáveis sob análise.

Para compor a fotografia sociolinguística do português falado no Brasil, é importante que se disponha, não só de um vasto acervo de amostras diversificadas, mas principalmente de amostras comparáveis entre si. O tipo de corpus mais utilizado em pesquisas variacionistas é formado pelas chamadas 'entrevistas sociolinguísticas', constituindo amostras socialmente estratificadas e representativas das comunidades de fala estudadas. No Brasil, há vários bancos de dados linguísticos organizados para realização de pesquisas variacionistas, entre os quais se situam o Projeto Varsul (Variação Linguística na Região Sul do Brasil), que reúne dados de fala da zona urbana dos três estados da Região Sul e, mais recentemente, também da zona rural, em algumas localidades; e o Projeto Vertentes do Português Rural do Estado da Bahia, que armazena dois acervos: um de fala vernácula do português afro-brasileiro (de comunidades rurais isoladas, muitas delas remanescentes de quilombos) e outro de fala vernácula do português rural (de comunidades rurais não marcadas etnicamente). Citamos esses dois Projetos, pois nossa discussão neste artigo se dará em torno de pesquisas realizadas a partir de amostras oriundas desses bancos de dados.

A comparabilidade de estudos acerca de um mesmo objeto é fundamental para a descrição de uma língua. É na comparação de resultados de diferentes pesquisas que melhor se compreende um fenômeno, seja na identificação de fatores condicionadores linguísticos e sociais, seja na observação das tendências probabilísticas de uso, ou ainda no enquadre teórico. Nesse sentido, a comparação deve contemplar, no âmbito das pesquisas sociolinguísticas, aspectos como: características sociais dos informantes, seleção da amostra, recorte do objeto, encaixe teórico, escolha de variáveis independentes, critérios para estabelecer os fatores controlados, análise dos resultados quantitativos. É importante que cada trabalho seja realizado e descrito de tal forma que permita replicação e análise comparativa.

Neste artigo, discutiremos alguns desses aspectos de ordem metodológica: a comparação de resultados tão somente em termos de percentuais, independentemente de peculiaridades das amostras envolvidas e das variáveis consideradas, e eventuais problemas de interpretação que podem daí advir. As reflexões aqui apresentadas foram motivadas pela leitura do trabalho de Meira (2006) acerca da variação entre o modo subjuntivo e o modo indicativo em dados orais oriundos de quatro comunidades rurais baianas, no qual a autora compara seus resultados com os de Pimpão (1999b), provenientes de estudo desse mesmo fenômeno linguístico em amostras de fala da 
capital catarinense, trazendo esses resultados como evidência em favor da existência de, pelo menos, duas gramáticas no português do Brasil (MEIRA, 2006, p. 07), uma do português afro-brasileiro e outra do português urbano ${ }^{1}$.

Assim, são os seguintes os objetivos do presente trabalho: i) discutir as implicações de uma análise focada em resultados frequenciais gerais; e ii) refletir sobre a importância do processo de organização de grupos de fatores e dos próprios fatores na comparação de resultados de diferentes pesquisas. Não é objetivo deste artigo discutir o referencial teórico de ambos os trabalhos, mas interpretações qualitativas a partir de resultados quantitativos.

O artigo está organizado da seguinte forma: como contextualização para discussão posterior, as pesquisas de Pimpão (1999b) e de Meira (2006) são apresentadas primeiramente, realçando-se aspectos metodológicos. Segue-se uma discussão em face de alguns resultados quantitativos gerais de ambos os estudos, usados comparativamente por Meira (2006) em sua dissertação, com especial atenção para um determinado grupo de fatores - tipo de verbo. Fechando o texto, as considerações finais.

\section{AS PESQUISAS DE PIMPÃO (1999b) e MEIRA (2006)}

A análise variável de tempo-modo verbal é o ponto de convergência das dissertações de mestrado de Pimpão (1999b) e de Meira (2006): a primeira analisa o processo de variação entre o presente do modo subjuntivo e o presente do modo indicativo; a última, os três tempos do modo subjuntivo na variação com os respectivos tempos do modo indicativo. Esta seção destina-se, então, a apresentar uma síntese do encaminhamento teórico-metodológico de ambos os estudos.

Pimpão (1999b) investiga a variação entre o presente do modo subjuntivo e o presente do modo indicativo em dados de fala da cidade de Florianópolis, considerando cinco contextos sintáticos de ocorrência de modo subjuntivo: orações substantivas, orações relativas, orações adverbiais, orações com 'talvez' e construções negativas realizando rodadas estatísticas individualizadas para cada contexto, em que a variável dependente é constituída pelas formas alternantes do indicativo e do subjuntivo. A autora procurou desvincular a associação entre morfologia flexional de modo subjuntivo e atitude de incerteza - associação essa que a gramática tradicional tratou de fortalecer ao longo da história -, substituindo-a por uma condição de variabilidade linguística. A hipótese norteadora do estudo centra-se no reconhecimento da relação entre as categorias de tempo e de modalidade, de um lado, e o modo subjuntivo, de outro.

A constituição da amostra analisada compreende dados de fala coletados de gravações de entrevistas transcritas e armazenadas no Banco de Dados do Projeto Varsul, mais especificamente da zona urbana da cidade de Florianópolis, de colonização açoriana. A estrutura sociolinguística aplicada à constituição do Banco distribui os informantes em sexo, idade, escolaridade, região e etnia. Os grupos de fatores sociais controlados nesse estudo estão assim distribuídos: sexo (masculino e feminino), idade (14 a 24, 25 a 50,

\footnotetext{
${ }^{1}$ Por português urbano entenda-se a referência que Meira faz à pesquisa de Pimpão (1999b), com dados de variação entre presente do subjuntivo e presente do indicativo na fala de florianopolitanos, e também à pesquisa de Rocha (1997) cuja amostra é identificada apenas como sendo de zona urbana.
} 
acima de 50 anos) e escolaridade (primário, ginásio, colegial). Um total de dezoito células foi analisado, com dois informantes por célula, constituindo trinta e seis informantes. Além das variáveis sociais, grupos de fatores linguísticos (especificados adiante) foram controlados nas rodadas com os cinco contextos sintáticos acima mencionados.

Como procedimento de coleta de dados, gramáticas tradicionais foram consultadas para a identificação dos contextos previstos pelos padrões normativos como de emprego do modo subjuntivo, mas que permitem também o uso do modo indicativo. Tomando como base esse critério, 319 dados $^{2}$ foram selecionados nas entrevistas, assim distribuídos pelos diferentes contextos sintáticos: 114 em orações substantivas, 72 em orações relativas, 75 em orações adverbiais, 36 em orações com talvez e 19 em construções intercaladas. ${ }^{3}$ Foram descartados da análise alguns tipos de dados: expressões cristalizadas (1-2), neutralização entre o presente do indicativo e o presente do modo subjuntivo (3) e cláusulas relativas com pronomes indefinidos, mas que remetem a um item linguístico definido no discurso (4). Após a coleta e o controle de grupos de fatores, os dados foram submetidos ao programa computacional VARBRUL. Considere os dados que se seguem.

(1) Não sei, mas tomara que dê, né? (FLP 21, L0666 ${ }^{4}$ )

(2) Então Deus te livre que elas escutem o que eu estou falando. (FLP 11, L0891)

(3) Olhando agora té deu uma acalmada, mas mesmo assim o povo ainda tem muita cicatriz daquela época e, acredito eu, que essas cicatrizes só vão ser saradas daqui a um bom tempo, né? (FLP 01, L1240)

(4) Cidade de Florianópolis. Uma capital bem sucedida de- Não digo bem, bem não, normalmente bem sucedida no transporte coletivo, não é uma cidade que lhe ofereça é, baixa inflação, porque é uma cidade que só tem funcionário público, não tem fábricas, então não tendo fábricas, não tem como baratear nada. (FLP 02, L0691)

A pesquisa de Pimpão (1999b) insere-se no quadro da Teoria da Variação laboviana, procurando sistematizar a heterogeneidade linguística mediante o controle probabilístico de grupos de fatores condicionantes, e também na proposta de gramática para a comunicação do Funcionalismo Linguístico de linha givoniana. Essa articulação teórica

\footnotetext{
${ }^{2}$ O número não expressivo de dados (319 ocorrências) não surpreende, tendo em vista a natureza das entrevistas. A fim de minimizar o paradoxo do observador, o pesquisador procura provocar situações de grande envolvimento do falante com o assunto, propiciando as chamadas narrativas de experiência pessoal, em que a atenção prestada à língua configura-se mínima, fazendo com que se instaure uma fala mais relaxada. Induzir o informante a falar mediante narrativas de experiência pessoal dificulta e inclusive inibe o uso da variável linguística em estudo, pois o modo subjuntivo tende a manifestar-se em perguntas acerca, por exemplo, da situação do país, da relação familiar, de perspectivas do bairro, da cidade, momentos em que o informante assume e defende um posicionamento.

3 Três dados da amostra apresentaram ambiguidade quanto à identificação do contexto sintático. Por exemplo: Ai, a gente acho que nunca imagina que talvez venha a passar por isso. (FLP 15, L0719), enquadra-se tanto no contexto com advérbio talvez como no contexto de oração substantiva (cf. PIMPÃO, 1999b, p. 126).

${ }^{4} \mathrm{O}$ código entre parênteses identifica a entrevista: FLP corresponde à cidade de Florianópolis, a primeira numeração refere-se ao número da entrevista e a segunda, o número da linha do dado.
} 
permite estudar o presente do modo subjuntivo como um fenômeno variável e desvincular a correlação entre as categorias de modo e modalidade, tratadas como categorias morfológicas pela tradição normativa, reinterpretando-as em termos de uma abordagem discursivo-pragmática de gramática que congrega estratégias linguísticas orientadas para o uso e responsáveis pela seleção de uma ou outra variante linguística: presente do modo subjuntivo ou presente do modo indicativo.

Em seu trabalho, Meira (2006) apresenta resultados acerca dos três tempos verbais do modo subjuntivo - presente, passado e futuro -, que variam com o modo indicativo em contextos de orações relativas e de orações completivas, a partir de dados coletados em quatro comunidades rurais afro-brasileiras do interior do estado da Bahia. Tendo como aparato teórico a Teoria da Variação laboviana e a Teoria da Transmissão Linguística Irregular, são duas as hipóteses de Meira (2006): os antepassados dos falantes dessas comunidades adquiriram o modo indicativo pelo contato do português com as línguas africanas, e o uso do modo subjuntivo está sendo favorecido pela difusão dos meios de comunicação e da infra-estrutura decorrentes da urbanização no país. O objetivo é verificar a frequência do subjuntivo nas quatro comunidades já mencionadas.

Para tratar de Transmissão Linguística Irregular, Meira cita, fundamentalmente, Lucchesi. Segundo o autor, o português não descende de uma língua crioula, o que não significa negar resquícios de um passado marcado pelo contato entre línguas: europeia, indígena e africana. Nesse sentido, a escravidão favoreceu essa proximidade, pois havia uma língua de superstrato e mais de uma língua de substrato, além da necessidade emergencial de comunicação aliada à ausência de uma ação normatizadora, favorecendo a transmissão irregular. Por transmissão irregular entende-se a ausência de uma instituição normatizadora da língua portuguesa.

Os dados para a pesquisa foram extraídos do Acervo de Fala Vernácula do Português Afro-Brasileiro, já mencionado. As amostras de fala são das seguintes comunidades rurais isoladas: Cinzento, Helvécia, Rio de Contas e Sapé ${ }^{5}$. Os informantes estão assim estratificados: sexo (masculino e feminino), idade (20 a 40, 41 a 60, 61 a 80 e acima de 80 anos - esta última faixa relativa apenas a Cinzento e Helvécia) e escolaridade (analfabeto e semi-analfabeto). Ainda foi controlada a variável período fora da comunidade: aqueles que viveram pelo menos seis meses fora da comunidade e aqueles que se ausentaram por um período inferior a esse. A amostra é constituída por 28 entrevistas: 8 em Cinzento e Helvécia e 6 em Rio de Contas e Sapé, e a seleção obedeceu aos pressupostos labovianos de minimizar o paradoxo do observador. Para o processamento quantitativo dos dados, a autora recorreu ao pacote estatístico VARBRUL.

Meira, após identificar os ambientes em que as formas verbais em estudo estariam potencialmente em variação, distribuiu os dados em dois contextos sintáticos, realizando rodas estatísticas diferenciadas: uma para as orações adjetivas (162 ocorrências) e outra para as orações completivas ( 80 ocorrências, das quais 45 estão no tempo presente), com variável dependente binária, i.e., presença vs. ausência do modo subjuntivo. Variáveis independentes foram consideradas, tanto de ordem social quanto

\footnotetext{
${ }^{5}$ Dessas comunidades, Meira (2006) informa que participou da constituição da amostra de Cinzento; das demais, a autora utilizou os corpora constituídos por outros pesquisadores.
} 
de ordem linguística (cf. retomado adiante). Alguns dados foram desconsiderados na análise, conforme exemplos a seguir (p. 182):

(5) 'Nas orações relativas:

(1) As ocorrências de orações relativas sem antecedente, como em:

(1a) Pra comprá os... o... o que come e uma... e a camisinha! (SubR_C12)

(2) As ocorrências de orações clivadas, do tipo:

(2a) ...tu ta forte, ta viveno, né... Né... né cabelo branco que faz idade não (SubR_C12)

(6) Nas orações completivas:

(3) As expressões independentes cristalizadas, do tipo:

(3a) Graças... Lôvado seja Deus! (SubC_H13)

(4a) (...) Deus ajuda que dá pa vim (SubC_R24)'

Os dados das duas pesquisas que permitem algum tipo de comparação são aqueles identificados por Pimpão como orações substantivas (114 ocorrências) e os de Meira identificados como orações completivas, limitados ao tempo presente (45 ocorrências).

\section{DISCUSSÃO EM TORNO DA COMPARABILIDADE DE RESULTADOS}

Para a discussão de natureza metodológica proposta neste artigo, tomamos como base algumas passagens da dissertação de Meira (2006), bem como alguns de seus resultados, em contraponto aos de Pimpão (1999b).

A primeira ressalva que queremos fazer diz respeito às amostras analisadas. $\mathrm{O}$ número de entrevistas consideradas por Meira (2006), bem como a distribuição das faixas etárias e o nível de escolaridade dos informantes, difere do número de entrevistas analisadas por Pimpão (1999b): 28 entrevistas para o primeiro estudo e 36 entrevistas para o segundo. Além disso, as 28 entrevistas de Meira (2006) estão distribuídas em quatro comunidades: Cinzento e Helvécia (cada qual com oito entrevistas) e Rio de Contas e Sapé (cada qual com 6); já Pimpão (1999b) valeu-se de dados da cidade de Florianópolis. Um problema metodológico, a nosso ver, reside na comparação, sem restrições, de resultados obtidos em análises de amostras cuja estratificação dos informantes é diferenciada, além de se opor quatro localidades, de um lado, e uma de outro.

Vejamos algumas ocorrências que ilustram o conjunto de dados analisados por ambas as autoras. Os dados (7 a 9) foram retirados da pesquisa de Meira (p. 236; 239); os demais, de Pimpão (p. 92; 93).

(7) Eles num gostam que ande entrano no mato p acaçá não? (SubC_S04)

(8) Até... pode sê que eu vô quand'eu tive... (SubC_H13)

(9) ...e se ela vem na nova, a gente espera, a gente espera q'ela vem naquele mesmo... (SubC_C06)

(10) Ah, só espero que o Brasil não perca hoje. (FLP 19, L0129)

(11) ...eu não sou o que eles querem que eu sou,... (FLP 05, L1425)

(12) Contando, ninguém acredita, né? ninguém vai acreditar, vai pensar que é mentira minha. (FLP 15, L0871) 
Observemos, agora, as Tabelas 1 e 2 que explicitam os contextos considerados, respectivamente, por ambas as autoras.

TABELA 1. Modo subjuntivo: tempo-modalidade e contexto de subjuntivo em Florianópolis (Extraída de PIMPÃO, 1999b, p. 110) ${ }^{6}$

\begin{tabular}{l|c|c}
\hline \multicolumn{1}{c|}{ Contextos } & Irrealis - futuridade & $\begin{array}{c}\text { Realis - atemporalidade, } \\
\text { incerteza, } \text { pressuposição }\end{array}$ \\
\hline Cláusulas substantivas & $70 / 83-84 \%$ & $10 / 31-32 \%$ \\
\hline Cláusulas relativas & $09 / 11-82 \%$ & $23 / 61-38 \%$ \\
\hline Cláusulas adverbiais & $15 / 19-79 \%$ & $22 / 56-52 \%$ \\
\hline Advérbio talvez & $11 / 14-79 \%$ & $13 / 22-59 \%$ \\
\hline Expressões intercaladas & - & $06 / 19-32 \%$ \\
\hline
\end{tabular}

A tabela anterior mostra todos os contextos analisados na pesquisa sobre a variação no tempo presente em dados de Florianópolis. Para fins específicos do presente artigo, será apenas considerado o contexto das orações substantivas. Observe-se que a Tabela 1 apresenta os dados distribuídos de forma cruzada: contextos sintáticos e tipo de modalidade. O total de orações substantivas analisadas é de 114 ocorrências das quais 80 estão no modo subjuntivo.

Já a tabela abaixo reproduzida apresenta resultados para o uso do modo subjuntivo em orações completivas segundo o tempo verbal desse mesmo modo, no português afrobrasileiro. Interessa, para o propósito desta discussão, a linha do presente do subjuntivo, tempo verbal comum aos dois estudos - já que Meira tece, em várias passagens de sua dissertação, comparações com a pesquisa de Pimpão (1999b).

TABELA 2. O uso do subjuntivo nas orações completivas no português afro-brasileiro segundo o tempo do subjuntivo previsto no uso culto (Extraída de MEIRA, 2006, p. 237)

\begin{tabular}{l|c|c}
\hline \multicolumn{1}{c|}{ Contexto de uso } & $\mathbf{N}^{\mathbf{0}}$ de ocorrências/Total & Frequência \\
\hline Imperfeito do subjuntivo & $11 / 33$ & $33 \%$ \\
\hline Presente do subjuntivo & $11 / 45$ & $24 \%$ \\
\hline TOTAL & $22 / 78$ & $28 \%$ \\
\hline
\end{tabular}

Meira (2006, p. 238), tomando como parâmetro de comparação os resultados percentuais de $84 \%$ de uso do presente do subjuntivo (Tabela 1) contra os $24 \%$ observados na Tabela 2, também para o presente do subjuntivo, reafirma a posição defendida na dissertação de que as diferenças entre o português urbano e o português afro-brasileiro são tão díspares que justificam diferenças de gramáticas. Essa análise suscita alguns questionamentos.

Cumpre esclarecer que, no estudo de Pimpão (1999b), foi controlada a variável tempomodalidade que recobre os fatores futuridade, atemporalidade, incerteza $\mathrm{e}$ pressuposição. O fator futuridade diz respeito a contextos de orações substantivas sob a modalidade irrealis, projetadas para o futuro, naturalmente incertas, e definidas como situações em que o falante não tem indícios consistentes para defender um ponto de vista, permitindo mais questionamentos e dúvidas por parte do ouvinte. Os demais fatores foram amalgamados sob o escopo da modalidade realis (algumas ocorrências

\footnotetext{
${ }^{6}$ Negritamos, nas tabelas, os resultados que são relevantes para a nossa discussão.
} 
situam-se, de fato, na interface irrealis-realis, mas discutir essa questão foge do objetivo deste artigo).

Vejamos alguns dados ilustrativos de contextos irrealis e realis da amostra analisada (dois de cada contexto).

(13) A hora que eles começarem a passar essa rua pela parte de baixo, ou na parte do mar que eles querem passar a Geral, ali, pode ser que melhore um pouco, o pessoal ficar mais tranquilo. Que hoje em dia, uma criança, pra atravessar a estrada, hoje, é um sufoco, né? (FLP 04, L0078)

(14) [É uma via que vai]- que está vindo direto do centro, que vai direto ao aeroporto, a via expressa que eles vão fazer aqui. Talvez aumente mais o bairro ainda, cresça mais. (FLP 14, L0058)

(15) Mas eu acredito que há uma força superior, né? (FLP 17, L1080)

(16) Ah, não é todos, é isso aí, mas é impossível que nesses todos não tem uma válvula de escape. (FLP 19, L1361)

As ocorrências (13) e (14) correspondem ao fator identificado por Pimpão como futuridade. Nesses casos, não há como fornecer provas concretas de que haverá mais tranquilidade (13) e de que o bairro crescerá (14), por isso o ouvinte tem mais condições de refutar possíveis argumentos dos falantes. Em (15) e (16), a crença em uma força superior e a possibilidade de existência de uma válvula de escape não são eventos projetados para o futuro; são situações que contemplam uma faixa temporal mais alargada, desde o passado, passando pelo presente e chegando ao futuro. É evidente que há um traço de incerteza atravessando todos os exemplos, mas a distinção marcada por Pimpão envolve, nesse caso, um traço de temporalidade.

A Tabela 1, conforme já apontamos, apresenta resultados de cruzamento de duas variáveis. Os três fatores da última coluna foram amalgamados sob o rótulo realis por terem apresentado isoladamente, na análise probabilística, pesos relativos próximos a 0,30 em oposição ao fator futuridade que apresentou um peso relativo superior a 0,70 (PIMPÃO, 1999b, p. 73).

Voltando à análise de Meira, o percentual de $84 \%$ tomado como parâmetro de comparação refere-se unicamente a contextos de orações substantivas sob a modalidade irrealis projetada para o futuro. Ela ignora os resultados dispostos na última coluna da Tabela 1. É preciso considerar que há outras orações substantivas que não envolvem somente uma projeção futura, mas abarcam o presente, podendo incluir o passado modalidade da atemporalidade-incerteza-pressuposição - que foram consideradas, na pesquisa sob o escopo de realis. Esse tipo de modalidade, ilustrada pelos dados (15) e (16), apresenta um baixo percentual para o uso do subjuntivo (32\%).

Assim, para o contexto irrealis, há uma aplicação de 70/83 para o uso do subjuntivo, com um percentual de $84 \%$ e, para o outro contexto, a aplicação é de $10 / 31$ para esse mesmo modo verbal, com um percentual de $32 \%$ (cf. Tabela 1). Se somarmos cada aplicação de subjuntivo, teremos um total de 80 ocorrências, o que dá um percentual de aproximadamente $70 \%$ para o emprego desse modo verbal. Esse resultado é que deveria ter sido tomado como parâmetro de comparação entre os dois trabalhos. 
Estreitando a análise, após a apreciação cerca da frequência geral de uso do presente do modo subjuntivo, passemos a verificar o efeito do contexto, em termos de condicionamento linguístico. As Tabelas 3 e 4 apresentam fatores em comum a ambos os trabalhos. Meira (2006) controlou o grupo de fatores tipo de verbo da oração, obtendo os resultados expostos na Tabela 3.

TABELA 3. O uso do subjuntivo nas orações completivas no português afro-brasileiro segundo o tipo do verbo da oração em que a completiva está encaixada (Extraída de MEIRA, 2006, p. 234)

\begin{tabular}{l|c|c}
\hline \multicolumn{1}{c|}{ Tipo de verbo } & $\mathbf{N}^{\mathbf{0}}$ de ocorrências/Total & Frequência \\
\hline Volitivos, avaliativos, inquiritivos & $10 / 23$ & $43 \%$ \\
\hline Causativos & $07 / 18$ & $39 \%$ \\
\hline Cognitivos & $03 / 32$ & $09 \%$ \\
\hline TOTAL & $23 / 80$ & $29 \%$ \\
\hline
\end{tabular}

A partir desses resultados, e fazendo referência à dissertação de Pimpão (1999b, p. 92) com ênfase no emprego do modo subjuntivo com verbos de cognição, Meira (2006, p. 235) afirma que "enquanto em nossos corpora o uso do subjuntivo nesse contexto é muito baixo, no português urbano é comum o emprego das formas de subjuntivo em completivas selecionadas por verbos cognitivos". Examinemos com mais cautela tal afirmação.

Pimpão (1999b) não controlou a variável tipo de verbo nos termos de Meira, mas observou a natureza epistêmica ou deôntica dos verbos da oração matriz. De fato, boa parte dos verbos de cognição (acreditar, pensar, imaginar etc) recaem sob o escopo da modalidade epistêmica. No entanto, Pimpão não apresenta resultados para essa variável, pois "a natureza epistêmica e deôntica das classes verbais abordadas não foi selecionada como um grupo estatisticamente significativo pelo programa computacional" (p. 92). Logo, a afirmação contida na citação do parágrafo anterior deve ser bastante relativizada.

Em outro estudo realizado por Pimpão (1999a), somente com orações substantivas, é verificada a atuação da variável tipo de verbo, à semelhança de Meira (2006, p. 234). Nessa pesquisa, Pimpão (1999a) controla duas faixas etárias (25 a 50 e acima de 50 anos), diferentemente de sua dissertação que inclui uma faixa etária mais jovem (14 a 24 anos). Meira (2006), conforme já mencionado, controla as seguintes faixas: 20 a 40, 41 a 60, 61 a 80 e acima de 80 anos. Se estabelecermos uma comparação entre os resultados de Pimpão (Tabela 4) e de Meira (Tabela 3), para os verbos de cognição, observamos resultados percentuais mais próximos.

TABELA 4. Uso do presente do modo subjuntivo na relação entre modalidade e tipo de verbo (Extraída de PIMPÃO,1999a, p. 581)

\begin{tabular}{l|cc|cc|cr|cc}
\cline { 2 - 9 } & \multicolumn{2}{|c|}{$\begin{array}{c}\text { Volitivo } \\
\text { Aplic./Total \% }\end{array}$} & \multicolumn{2}{c|}{ Manipulativo } & \multicolumn{2}{c|}{$\begin{array}{c}\text { Cognição } \\
\text { Aplic./Total \% }\end{array}$} & \multicolumn{2}{c}{$\begin{array}{c}\text { Enunciação } \\
\text { Aplic./Total \% }\end{array}$} \\
Aplic./Total \% \\
\hline Deôntico & $21 / 22$ & 95 & $11 / 20$ & 55 & $0 / 4$ & 0 & $0 / 0$ & 0 \\
\hline Epistêmico & $0 / 0$ & 0 & $0 / 0$ & 0 & $3 / 14$ & 21 & $0 / 13$ & 0 \\
\hline Epistêmico alto & $0 / 0$ & 0 & $0 / 1$ & 0 & $0 / 26$ & 0 & $0 / 24$ & 0 \\
\hline
\end{tabular}


Considerando as Tabelas 3 e 4, o fator verbos cognitivos de Meira (2006) aproxima-se, de certo modo, do fator epistêmico de Pimpão (1999a), pois, de acordo com a Tabela 4, verbos epistêmicos abarcam tanto verbos de cognição quando de enunciação. Assim, temos os seguintes percentuais: 9\% (cf. Tabela 3) e 21\% (cf. Tabela 4) para subjuntivo com verbos de cognição. Analisando esses resultados, percebemos que os percentuais se aproximam, sugerindo um comportamento variável do subjuntivo semelhante entre as localidades investigadas.

Ademais, não podemos esquecer que Meira (2006), na Tabela 3, controla os três tempos verbais do subjuntivo, enquanto Pimpão (1999a), na Tabela 4, analisa apenas o presente desse modo verbal. Se tivéssemos os resultados de Meira (2006) somente para o tempo presente, o percentual poderia mudar, para mais ou para menos. De qualquer forma, como a análise de Meira (2006) parte dos percentuais apresentados, não importando o tempo verbal, também partimos desse mesmo resultado para colocar em discussão os argumentos da autora.

\section{CONSIDERAÇÕES FINAIS}

Gostaríamos de deixar registrado que não estamos colocando em questionando o mérito indiscutível da pesquisa de Meira, que investiga a variação entre o uso do modo indicativo e subjuntivo em comunidades que descendem de escravos, comunidades essas marcadas, historicamente, pelo contato do europeu com os africanos. $\mathrm{O}$ foco de discussão deste artigo, que toma a análise de Meira (2006) como ponto de partida, é a problemática que envolve generalizações feitas a partir de resultados percentuais e nem sempre adequadamente comparáveis entre si.

No caso de pesquisas realizadas no âmbito da sociolinguística variacionista, chamamos a atenção para o fato de que qualquer comparação de resultados deve observar rigorosamente o processo metodológico que envolve os estudos em questão, desde as características das comunidades de fala, o perfil social dos informantes, a exata delimitação do objeto de análise, os dados desconsiderados, até as variáveis independentes estabelecidas para controle e, especialmente, os critérios utilizados para definir cada fator dessas variáveis. Além disso, há que se fazer uma distinção entre resultados percentuais e probabilísticos, e ter cautela ao se comparar resultados que são meramente frequenciais.

Ademais, no caso específico do trabalho de Meira (2006) que deu origem às reflexões aqui desenvolvidas, julgamos ser temeroso fazer afirmações em termos de confirmação de hipóteses acerca da coexistência de uma gramática do português urbano e outra do português afro-brasileiro, considerando como evidência comparações de resultados construídas com pouca consistência, como acreditamos ter mostrado ao longo do artigo. Não estamos negando a existência dessas diferentes gramáticas, tão somente questionando tal afirmação feita com base em percentuais de frequências gerais e comparações de contextos e fatores não inteiramente coincidentes. Conforme Guy (2001), o uso geral de um fenômeno é uma das etapas de comparação entre diferentes estudos; o efeito de contexto também deve ser criteriosamente observado. 


\section{REFERÊNCIAS}

GUY, G. As comunidades de fala: fronteiras internas e externas. Abralin, 2001.

LABOV, W. Sociolinguistic patterns. Philadelphia: University of Pennsylvania, 1972.

MEIRA, V. O uso do modo subjuntivo em orações relativas e completivas no português afro-brasileiro. Salvador: UFBA, 2006. Dissertação de Mestrado.

PIMPÃO, T. S. Modo subjuntivo: complexidade superior à idealização da tradição gramatical. In: Anais da XVI Jornada de Estudos Linguísticos do Nordeste. Fortaleza: UFC/GELNE, 1999a. p. 578-582.

- Variação no presente do modo subjuntivo: uma abordagem discursivopragmática. Florianópolis: UFSC, 1999b. Dissertação de Mestrado.

ROCHA, R. C. F. (1997). A alternância indicativo/subjuntivo nas orações subordinadas substantivas em português. Brasília: UnB, 1997. Dissertação de Mestrado. 